\title{
Selecting the best mobile model by applying AHP-COPRAS and AHP-ARAS decision making methodology
}

\author{
Shankha Shubhra Goswami ${ }^{a^{*}}$ and Soupayan Mitrab
}

\begin{abstract}
${ }^{a}$ PhD student, Department of Mechanical Engineering, Indira Gandhi Institute of Technology, Post: Sarang, District: Dhenkanal, Odisha, India ${ }^{b}$ Associate Professor, Department of Mechanical Engineering, Jalpaiguri Government Engineering College, Post \& District: Jalpaiguri, West Bengal, India

\section{H R O N I C L E}

Article history:

Received: July 1, 2019

Received in revised format: July

22, 2019

Accepted: August 30, 2019

Available online: August 30, 2019

Keywords:

Mobile

MCDM

COPRAS

ARAS

$A H P$

\section{A B S T R A C T}

The main objective of this research article is to select the best mobile model among various alternatives available on the market. For this analysis 10 alternative models from different brands are selected from different online shopping website having different specifications and ranging from low budget to medium budget in terms of price. For this selection purposes two multiple criteria decision making tools (MCDM) has been adopted i.e. Complex Proportional Assessment (COPRAS) and Additive Ratio Assessment (ARAS). The selection process is done based on four important criteria i.e. price, internal storage, RAM and brand. The weightages of the criteria are calculated by using Analytic Hierarchy Process (AHP) and these weightages are further used in COPRAS and ARAS methods. Individual COPRAS and ARAS method is applied for the selection of the best mobile and the preference ranking order of the models are also proposed by each process. The proposed ranking order by both the methods are compared and it is found that the outcome results are more or less the same using both techniques but there is a slight change in ranking of the middle-order alternatives. Both processes give model 1 and model 4 as the best and the worst models respectively among 10 alternatives.
\end{abstract}

\section{Introduction}

In this ever developing and technological revolutionary world, electronic gadgets hold the most attention of the common people and researchers are continuously working in this area to develop the technologies more and more. For the last few years several electronic gadgets e.g. mobiles, laptops, tablets added values and provides much importance towards the people's life (Mitra \& Goswami, 2019a). It became an essential requirement in our daily life (Mitra \& Goswami, 2019a) to make our survival easier and smoother in this era of competitive market. Now a day's mobile phones have become an essential and one of the most important requirements in everyone's life among other electronic gadgets (Mitra \& Goswami, 2019a). Day by day, different companies are launching various new model of mobile phones all

* Corresponding author. Tel.: +919051334009

E-mail address: shankhashubhragoswami@gmail.com (S. S. Goswami) 
over the world having new features and more updated technical specifications which causes lots of confusion among the buyers, so it is quite very difficult to choose an appropriate mobile model among lots of other different available models in the market (Mitra \& Goswami, 2019a; Mitra \& Goswami, 2019b) and moreover, there are also lots of conflicting criteria's (Madurika \& Hemakumara, 2015) associated with it. As a whole, this situation can be seen as a multiple criteria decision making (MCDM) problem (Velasquez \& Hester, 2013; Bhole \& Deshmukh, 2018), which draws the attention of the decision makers and forced them to work on this field.

This research paper aims to deal with such confusing situations and tried to provide a solution. For this analysis 10 different mobile models ranging from low budget to medium budget are chosen from different brands and are having different specifications which are available in different online shopping websites. The main goal of this study is to select the best model among these 10 available models in the market. The selection process is done based on four important criteria i.e. price, internal storage, RAM and brand. The full technical specifications and the model name of the selected mobile phones are given in Table 6 .

There are lots of MCDM techniques are there like AHP (Saaty, 1980; Saaty, 2008), TOPSIS (Hwang \& Yoon, 1981; Yoon, 1987; Hwang et al., 1993), VIKOR (Opricovic \& Tzeng, 2004; Opricovic \& Tzeng, 2007), ELECTRE (Roy, 1968), PROMETHEE (Brans, 1982), MOORA (Brauers \& Zavadskas, 2006; Brauers \& Zavadskas, 2009), Fuzzy-AHP (Buckley, 1985; Chang, 1996) etc. and these can be applied in wide variety of areas which are explained in details in the literature review section. However, among these MCDM tools two techniques has been adopted for this analysis i.e. COPRAS (Zavadskas et al., 2008) and ARAS (Zavadskas \& Turkis, 2010; Zavadskas et al. 2010). Many researchers adopted these two techniques and used it as a decision making tools to solve problems in different areas like environmental issues (Marzouk \& Abdelakder, 2019), education (Das et al., 2012), agricultural problems (Iisik $\&$ Adali, 2016), vendor selection (Chatterjee and Bose, 2013a; madic et al., 2014) etc. but very few works has been reported that these methodologies is being utilized for solving the decision problems associated with our daily life and the selection of electronic gadgets e.g. laptop selection (Adali \& Isik, 2017; Mitra \& Goswami, 2019b), refrigerator selection (Mitra \& Kundu, 2017; Mitra \& Kundu, 2018), air-conditioner selection (Adali \& Isik, 2016), washing machine selection etc. Hence, there is a huge scope to apply these MCDM techniques in such areas and ranking of the alternatives can be done. In this paper, initially all the criteria weights are found out by applying AHP and further these weightages are utilized in COPRAS and ARAS methodology. The best mobile model and a preference ranking order of the models from best to worst are proposed by both the methodologies and at last, both the rankings are compared which is shown in Table 17 and also shown graphically in Fig. 1.

\section{Literature Review}

As already mentioned, that MCDM methods have been adopted by different researchers and applied in wide variety of areas. In recent few years various MCDM tools find its applications in manufacturing industry (Duran \& Aguilo, 2008; Rostamzadeh \& Sofian, 2011), shipping industry (Celik et al., 2009; Bulut et al., 2012), telecommunication industry (Bentes et al., 2012), electronic industry (Yang et al., 2009; sun, 2010), hydrology and water management (Qin et al., 2008; Chung and Lee, 2009), environmental management (Geldermann et al., 2000; Vaillancourt \& Waaub, 2004), energy management (Kowalski et al., 2009; Tsoutsos et al., 2009), project management and evaluation (Sowlati et al., 2005), transportation and logistics (Tzeng et al., 2005; Efendigil et al., 2008) etc. Liu et al. (2000) evaluate the overall supplier performances by using data envelopment analysis (DEA) and later, Madic et al. (2014) analyzed the same problem by using COPRAS method. By using COPRAS method Andruškevicius (2005) evaluated the contractors. Viteikiene and Zavadskas (2007) evaluate residential areas sustainability of Vilnius City by using COPRAS method. Banaitiene et al. (2008) implemented COPRAS method to determine a building's life cycle. Kumar and Roy (2010) develop a hybrid method of AHP and artificial neural network (ANN) to determine the Performance of the suppliers. 
Chamzini and Yakhchali (2012) proposed a new hybrid model based on FAHP and FTOPSIS to select the proper handling system. Karande and Chakraborty (2012) solved the enterprise resource planning (ERP) system selection problem by using fuzzy theory and MOORA method. Rostampour (2012) proposed the best internet browser by implementing TOPSIS method based on five criteria i.e. support configurations, features, speed, technical support and security. Chatterjee and Bose (2013a) presented ARAS method in their paper for vendor selection of a wind farm and the outcome results was also validated by COPRAS technique. In the same year, Chatterjee and Bose (2013b) adopted COPRAS method for the site selection of wind farm under fuzzy environment. Barak et al. (2014) used fuzzy ARAS and fuzzy TOPSIS methods to select a well for hydraulic fracturing treatment. Bhattacharya and Chakraborty (2014) developed a DEA-TOPSIS combined approach for evaluating the performance of eight IITs. Ghadikolaei et al. (2014) determined the financial performance of companies under fuzzy environment, FAHP is used to calculate the weights of the criteria and F-ARAS, F-VIKOR, F-COPRAS is used to rank the alternatives.

Bose and Chatterjee (2016) applied a hybrid MCDM concept of fuzzy ARAS and fuzzy MOORA methodology for the selection of wind turbine service technicians based on five criteria. Chagooshi et al. (2016) employed hybrid fuzzy approach for the best suitable project manager selection where fuzzy DEMATEL was used to prioritize the importance of various criteria and fuzzy VIKOR was used to rank the alternatives. Dey and Chakraborty (2016) implemented grey TOPSIS method to study the machinability of metal alloys of three materials i.e. aluminium, copper and steel. Isik and Adali (2016) solved the agricultural tractor selection problem by using TOPSIS method and the results are compared by analyzing through COPRAS and EVAMIX techniques. Karande et al. (2016) shows the ranking performance of six different MCDM techniques by investigating through an industrial robot selection problem. An integrated approach of MACBETH and COPRAS is adopted by Kundakci and Isik (2016) to select the air compressor for a spinning mill of a textile company, where MACBETH is used for determining the weights of the criteria's and COPRAS is used to rank the alternatives. Paul et al. (2016) used the ARAS method to evaluate the police performance in different states and union territories of India in order to decrease the crime rate by taking immediate actions on the poor under performing police force of the state. Rathi et al. (2016) developed a project selection approach by using fuzzy based VIKOR and TOPSIS methodology by considering seven criteria and the weights are evaluated by using modified digital logic (MDL) method.

Anyache et al. (2017) adopted fuzzy TOPSIS for the portfolio selection of banking services. Garg and Jain (2017) applied COPRAS, VIKOR and weighted distance based approximation (WDBA) method for selecting the e-learning websites. Prasad et al. (2017) presented a hybrid methodology of AHP, data envelopment analysis (DEA) and grey relational analysis (GRE) for the selection of best efficient supplier. Mirahmadi and Ketabi (2018) develop a fuzzy analytic network process (ANN) to evaluate the employee performance. Prasad and Chakraborty (2018) applied modified similarity-based method for cutting fluid selection. Zare et al. (2018) implemented the grey group TOPSIS and fuzzy group VIKOR methods to choose an appropriate computerized maintenance software (CMMS) for a dairy company which was done based on 13 sub-criteria under 5 main criteria and finally the outcome results were compared. Biswas and Saha (2019) presented a paper, where a new MCDM technique is proposed for the selection of scooters and the results were compared with the outcomes obtained from TOPSIS and MABAC methods. Koganti et al. (2019) applied a hybrid MCDM method of GRA-AHP-TOPSIS for supplier selection problem. Marzouk and Abdelakder (2019) used weighted sum model (WSM), COPRAS and TOPSIS method to minimize the environmental emissions in construction projects and also proposed that these three methods provide the best ranking of the alternatives.

However, beside these applications lots of researchers also adopted and applied different MCDM techniques for the decision making and selection purposes of electronic gadgets e.g. Kundakci et al. (2015) solved the air conditioner selection problems by applying MOORA and further, Adali and Isik (2016) reconsidered the same problem and solved by applying COPRAS and ARAS methodology. Mitra and 
Kundu (2017) applied AHP method for the domestic refrigerator selection process and later, Mitra and Kundu (2018) analyzed the same problem by applying TOPSIS methodology. Mitra and Goswami (2019a) adopted a hybrid AHP-TOPSIS methodology for the selection of best desktop computer model and the same problem is validated by Mitra and Goswami (2019c) by implementing simple average weighting method (SAW). Also, Mitra and Goswami (2019b) select the best laptop model and gave a preference ranking order of six available laptop models in their paper by analyzing through AHP-SAW hybrid MCDM process.

\section{Theoretical Analysis}

This section consists all the theoretical details of AHP, COPRAS and ARAS methodology. All the steps are explained in details below under the sub-section 3.1, 3.2 and 3.3.

\subsection{Analytic Hierarchy Process (AHP)}

Analytic hierarchy process (AHP) was first developed by Thomas. L. Saaty (Saaty, 1980) in 1970s. AHP based on the principle of calculation of criteria weightages by creating a pair-wise comparison matrix and checking of consistency. AHP is adopted for this analysis to find out the four criteria weightages considered for this research purposes i.e. price, internal storage, RAM and brand. The AHP steps and the weightages calculation details are shown in the following steps below.

Step 1: Creating a pair-wise comparison matrix $(n \times n)$ according to Saaty's pair-wise comparison scale shown in Table 3, where $n$ is the number of criterions. Here, $\mathrm{n}=4$ for this case. The pair-wise comparison matrix is shown in Table 1 below.

Table 1

Pair-wise Comparison Matrix of the Criteria's

\begin{tabular}{ccccc}
\hline Comparisons & Price & Internal Storage & RAM & Brand \\
\hline Price & 1 & 5 & 4 & 7 \\
Internal Storage & $1 / 5$ & 1 & $1 / 2$ & 3 \\
RAM & $1 / 4$ & 2 & 1 & 3 \\
Brand & $1 / 7$ & $1 / 3$ & 5.83333 & 1 \\
\hline Sum & 1.59286 & 8.33333 & 14 \\
\hline
\end{tabular}

Step 2: Normalization of the pair-wise comparison matrix is done by using Eq. 1 shown below and the normalization matrix is shown in Table 2.

$$
N_{i j}=\frac{a_{i j}}{\sum_{i=1}^{n} a_{i j}}
$$

where, $i=1,2,3 \ldots, n$ and $j=1,2,3 \ldots, n$

In Eq. $1, a_{i j}$ is the value of the ith row and $j$ th column cell in Table 1.

Table 2

Normalization Matrix

\begin{tabular}{ccccccc}
\hline Comparison & Price & Internal Storage & RAM & Brand & Row Average & Weight \% \\
\hline Price & 0.62780 & 0.60000 & 0.68571 & 0.50000 & 0.60338 & 60.338 \\
Internal Storage & 0.12556 & 0.12000 & 0.08571 & 0.21429 & 0.13639 & 13.639 \\
RAM & 0.15695 & 0.24000 & 0.17143 & 0.21429 & 0.19567 & 19.567 \\
Brand & 0.08969 & 0.04000 & 0.05714 & 0.07143 & 0.06456 & 6.456 \\
\hline Sum & 1 & 1 & 1 & 1 & 1 & 100 \\
\hline
\end{tabular}

Step 3: The row average matrix $\left(6^{\text {th }}\right.$ column in Table 2$)$ is multiplied with the pair-wise comparison matrix (i.e. Table 1) to determine the consistencies of each and every criterion as shown below. 


$\left[\begin{array}{l}0.60338 \\ 0.13639 \\ 0.19567 \\ 0.06456\end{array}\right] \times\left[\begin{array}{cccc}1 & 5 & 4 & 7 \\ 1 / 5 & 1 & 1 / 2 & 3 \\ 1 / 4 & 2 & 1 & 3 \\ 1 / 7 & 1 / 3 & 1 / 3 & 1\end{array}\right]=\left[\begin{array}{l}2.51995 \\ 0.54859 \\ 0.81298 \\ 0.26145\end{array}\right] \Rightarrow\left\{\begin{array}{l}2.51995 / 0.60338 \\ 0.54859 / 0.13639 \\ 0.81298 / 0.19567 \\ 0.26145 / 0.06456\end{array}\right\}=\left\{\begin{array}{l}4.17639 \\ 4.02223 \\ 4.15496 \\ 4.04940\end{array}\right\}\left\|\begin{array}{c}\text { Price } \\ \text { Int Sto } \\ \text { RAM } \\ \text { Brand }\end{array}\right\|$

Step 4: Consistency checking.

Consistency is checked to ensure whether the decision maker judgements is true and consistent. For consistency checking, consistency index (CI) and consistency ratio (CR) is found out by using Eq. (2) and Eq. (3) respectively as shown in details below.

Average Consistency $\left(\lambda_{\max }\right)=\frac{4.17639 \quad .02223+4.15496+4.04940}{4}=4.10074$

$$
\text { Consistency Index }(\mathrm{CI})=\frac{\left(\lambda_{\max }-n\right)}{(n-1)}
$$

where, $\lambda_{\max }$ is the average consistency and $n$ is the number of criteria. Here, $\mathrm{n}=4$ for this case.

Hence, $\mathrm{CI}=\frac{(4.10074-4)}{(4-1)}=0.03358$

Consistency Ratio $(\mathrm{CR})=\frac{C I}{R I}$

where, RI is the randomly generated consistency index value. The RI values are given in Table 4

$$
\mathrm{CR}=\frac{0.03358}{0.9}=0.03731
$$

For $\mathrm{n}=4$, the RI value is given as 0.9 in Table 4

Since, the CR value is less than $0.1(0.03731<0.1)$ then it can be assured that the decision maker judgements are true and consistent. In this type of decision making problems up to $10 \%$ of inconsistency can be allowed but beyond that, the pair-wise comparison matrix needs to be modified so that the CR value restricts within $10 \%$ i.e. 0.1 .

Table 3

Saaty's Comparisons Scale

$\begin{array}{lc}\begin{array}{l}\text { Saaty's pair wise } \\ \text { comparison scale }\end{array} & \begin{array}{c}\text { Compare factor } \\ \text { of } i \& j\end{array}\end{array}$

\begin{tabular}{cc}
\hline 1 & Equal Importance \\
3 & Moderate Importance \\
5 & Strong Importance \\
7 & Very Strong or Demonstrated Importance \\
9 & Extreme Importance \\
$2,4,6,8$ & Intermediate values when compromise is needed \\
\hline
\end{tabular}

\section{Table 4}

Randomly Generated Consistency Index (RI)

\begin{tabular}{ccccccccccccc}
\hline $\mathrm{n}$ & 1 & 2 & 3 & 4 & 5 & 6 & 7 & 8 & 9 & 10 & 11 & 12 \\
\hline $\mathrm{RI}$ & 0 & 0 & 0.58 & 0.9 & 1.12 & 1.24 & 1.32 & 1.41 & 1.45 & 1.49 & 1.51 & 1.58 \\
\hline
\end{tabular}

\subsection{Complex Proportional Assessment (COPRAS)}

Zavadskas et al. (2008) firstly introduced the COPRAS method. This method considers the minimizing and the maximizing criteria separately (Madic et al., 2014) which influences the proportional dependence and degree of utility of the alternatives (Chatterjee and Chakraborty, 2014; Adali and Isik, 2016). The following are the steps of COPRAS method as described by Adali and Isik (2016).

Step 1: Create a $m \times n$ decision matrix shown by Eq. (4) according to Hwang and Yoon (1981) comparison scale shown in Table 5. Here, $m$ is the number of alternatives and $n$ is the number of criterions. 


$$
X=\left[x_{i j}\right]_{m \times n}=\left[\begin{array}{cccc}
x_{11} & x_{12} & \ldots & x_{1 n} \\
x_{21} & x_{22} & \ldots & x_{2 n} \\
\ldots & \ldots & \ldots & \ldots \\
x_{m 1} & x_{m 2} & \ldots & x_{m n}
\end{array}\right]
$$

where, $i=1,2,3 \ldots, m$ and $j=1,2,3 \ldots, n$

\section{Table 5}

Hwang and Yoon Comparison Scale

\begin{tabular}{ccccccc}
\hline Qualitative Estimation & Bad & Good & Average & Very Good & Excellent & Types of Criteria \\
\hline Quantitative Estimation & 1 & 3 & 5 & 7 & 9 & Max \\
& 9 & 7 & 5 & 3 & 1 & Min \\
\hline
\end{tabular}

Step 2: Normalization of the decision matrix by following the linear normalization method (Kaklauskas et al., 2006) as shown in Eq. (5).

$$
R=\left[r_{i j}\right]_{m \times n}=\frac{x_{i j}}{\sum_{i=1}^{m} x_{i j}}
$$

where, $i=1,2,3 \ldots, m$ and $j=1,2,3 \ldots ., n$

Step 3: Create the weighted normalized decision matrix $\left(D_{m \times n}\right)$ by multiplying the criteria weights with the elements of their respective column as shown in Eq. (6).

$$
D=\left[d_{i j}\right]_{m \times n}=r_{i j} \times w_{j}
$$

where, $i=1,2,3 \ldots, m$ and $j=1,2,3 \ldots ., n$

In Eq. (6), $w_{j}$ is the criteria weightages.

Step 4: The normalized weighted values of the beneficial criteria as well as the non-beneficial criteria are added separately for each and every alternative as given by Eq. (7) and Eq. (8).

$$
\begin{aligned}
& S_{+i}=\sum_{j=1}^{n} d_{+i j} \\
& S_{-i}=\sum_{j=1}^{n} d_{-i j}
\end{aligned}
$$

where, $d_{+i j}$ and $d_{-i j}$ are the normalized weighted values of the beneficial and the non-beneficial criteria. Now, bigger the value of $S_{+i}$ better is the alternative and lesser the value of $S_{-i}$ better is the alternative (Adali \& Isik, 2016). The degree of goals achieved by each alternative is expressed by $S_{+i}$ and $S_{-i}$ (Adali $\&$ Isik, 2016). The summation of the $S_{+i}$ and $S_{-i}$ values are done as expressed by Eq. (9) and Eq. (10).

$$
\begin{aligned}
& \sum_{i=1}^{m} S_{+i}=\sum_{i=1}^{m} \sum_{j=1}^{n} d_{+i j} \\
& \sum_{i=1}^{m} S_{-i}=\sum_{i=1}^{m} \sum_{j=1}^{n} d_{-i j}
\end{aligned}
$$

Step 5: Calculate the relative significance $\left(Q_{i}\right)$ of each alternative using Eq. (11).

$$
Q_{i}=S_{+i}+\frac{S_{-\min } \sum_{i=1}^{m} S_{-i}}{S_{-i} \sum_{i=1}^{m}\left(S_{-m i n} / S_{-i}\right)}=S_{+i}+\frac{\sum_{i=1}^{m} S_{-i}}{S_{-i} \sum_{i=1}^{m}\left(1 / S_{-i}\right)}
$$


where, $S_{\text {-min }}$ is the smallest or minimum value among the $S_{-i}$ values. Higher the $Q_{i}$ value, better is the alternative. The alternative with the highest relative significance value $\left(Q_{i}\right)$ is the best choice alternative and is denoted by $Q_{\max }$ (Adali \& Isik, 2016).

Step 6: Calculate the quantitative utility of each alternative $\left(U_{i}\right)$ by using Eq. (12).

$$
U_{i}=\left[\frac{Q_{i}}{Q_{\max }}\right] \times 100
$$

The utility value of each alternative ranges from $1 \%$ to $100 \%$. The priorities of each alternative are found out with respect to the most ideal and efficient one (Adali \& Isik, 2016). The alternative with the highest quantitative utility value $U_{i}$ is termed as the best alternative and the ranking is done from best to worst according to the decreasing values of $U_{i}$.

\subsection{Additive Ratio Assessment (ARAS)}

Zavadskas and Turkis (2010) firstly introduced the ARAS method through an evaluation of microclimate in office rooms to explain this method. It determines the degree of utility or performance of each alternatives with respect to an ideal alternative (Adali and Isik, 2016). The ARAS steps are adopted from Adali and Isik (2016) which are described as follows.

Step 1: Create a $m \times n$ decision matrix shown by Eq. (4) according to Hwang and Yoon (1981) comparison scale shown in Table 5.

Step 2: Normalization of the decision matrix by using Eq. (13) and Eq. (15) based on the nature of the criteria.

Normalization of the beneficial criteria is done by using Eq. (13)

$$
R=\left[r_{i j}\right]_{m \times n}=\frac{x_{i j}}{\sum_{i=1}^{m} x_{i j}}
$$

Normalization of the non-beneficial criteria is done in two steps shown by using Eq. (14) and Eq. (15). In the first stage, all the reciprocal of the non-beneficial elements needs to be found out according to Eq. (14) and in the second stage, the normalization is being done according to Eq. (15).

$$
\begin{aligned}
& x_{i j}^{*}=\frac{1}{x_{i j}} \\
& R=\left[r_{i j}\right]_{m \times n}=\frac{x_{i j}^{*}}{\sum_{i=1}^{m} x_{i j}^{*}}
\end{aligned}
$$

where, $i=1,2,3 \ldots, m$ and $j=1,2,3 \ldots, n$

Step 3: Calculate the weighted normalize matrix as shown in Eq. (16).

$$
D=\left[d_{i j}\right]_{m \times n}=r_{i j} \times w_{j}
$$

where, $i=1,2,3 \ldots, m$ and $j=1,2,3 \ldots, n ; w_{j}$ is the weightages of the criteria.

Step 4: Calculate the optimality function $\left(S_{i}\right)$ for each alternative according to Eq. (17).

$$
S_{i}=\sum_{j=1}^{n} d_{i j}
$$

where, $i=1,2,3 \ldots, m$ and $j=1,2,3 \ldots, n$ 
Step 5: Determine the degree of utility $\left(U_{i}\right)$ for each alternative by using Eq. (18).

$$
U_{i}=\left[\frac{S_{i}}{S_{0}}\right] \times 100
$$

where, $S_{0}$ is the optimality function value of the optimal alternative. The degree of utility values $\left(U_{i}\right)$ ranges from $0 \%$ to $100 \%$. It determines the relative efficiency of an alternative over the best optimal alternative (Chatterjee \& Chakraborty, 2014). The alternative with the highest degree of utility value is termed as the best alternative and the preference ranking order of the alternatives are done in decreasing order of $U_{i}$ values indicating best to worst.

\section{Research Methodology}

This section of the research article consists of all the experimental and calculation details of COPRAS and ARAS methodology. The selected mobile models and their specifications are given in Table 6 .

Table 6

Selected Mobile Models and their Specifications

\begin{tabular}{cccccc}
\hline Models & Price & Internal Storage & RAM & Brand & Mobile Name \\
\hline Mobile 1 & $80 \$$ & $16 \mathrm{~GB}$ & $2 \mathrm{~GB}$ & Redmi & Redmi 7a \\
Mobile 2 & $110 \$$ & $32 \mathrm{~GB}$ & $2 \mathrm{~GB}$ & Samsung & Samsung Galaxy A10 \\
Mobile3 & $130 \$$ & $64 \mathrm{~GB}$ & $4 \mathrm{~GB}$ & Samsung & Samsung J6 \\
Mobile 4 & $185 \$$ & $64 \mathrm{~GB}$ & $4 \mathrm{~GB}$ & Oppo & Oppo K1 \\
Mobile 5 & $135 \$$ & $64 \mathrm{~GB}$ & $3 \mathrm{~GB}$ & Realme & Realme 3 \\
Mobile 6 & $140 \$$ & $32 \mathrm{~GB}$ & $3 \mathrm{~GB}$ & Redmi & Redmi Note 7s \\
Mobile 7 & $185 \$$ & $64 \mathrm{~GB}$ & $6 \mathrm{~GB}$ & Honor & Honor 10 Lite \\
Mobile 8 & $110 \$$ & $16 \mathrm{~GB}$ & $3 \mathrm{~GB}$ & Asus & Asus Zenfone 2 Laser \\
Mobile 9 & $120 \$$ & $16 \mathrm{~GB}$ & $4 \mathrm{~GB}$ & Asus & Asus Zenfone 2 \\
Mobile 10 & $340 \$$ & $128 \mathrm{~GB}$ & $6 \mathrm{~GB}$ & Redmi & Redmi K20 Pro \\
\hline
\end{tabular}

The selected 10 mobile models and their specifications are shown in Table 6. Four criteria (i.e. price, internal storage, RAM and brand) are considered for this analysis out of which one criterion is nonbeneficial i.e. the price, whose minimum value is desired and the other three criteria are beneficial i.e. internal storage, RAM and brand, whose maximum values are desired. Here, in Table 6 the linguistic terms of brand are converted into crisp numeric values according to Table 5 where the maximum value represents the best choice and the minimum value represents the worst choice. After doing some researches and by interacting with some of the mobile users it is found that Samsung is the most preferable brand among the customers followed Honor and Redmi, so Samsung is replaced by number 9 since it is the best choice among all brands followed by Honor as number 7 for second choice and Redmi as number 5 for third choice. In this way the linguistic terms of brand are converted into quantitative values based on the opinions of some customers and electronic stores as shown in Table 7.

\subsection{Application of COPRAS}

Table 7

Decision Matrix

\begin{tabular}{|c|c|c|c|c|}
\hline Goal Type & Min & Max & Max & Max \\
\hline Models & Price & Internal Storage & RAM & Brand \\
\hline Mobile 1 & 80 & 16 & 2 & 5 \\
\hline Mobile 2 & 110 & 32 & 2 & 9 \\
\hline Mobile3 & 130 & 64 & 4 & 9 \\
\hline Mobile 4 & 185 & 64 & 4 & 1 \\
\hline Mobile 5 & 135 & 64 & 3 & 4 \\
\hline Mobile 6 & 140 & 32 & 3 & 5 \\
\hline Mobile 7 & 185 & 64 & 6 & 7 \\
\hline Mobile 8 & 110 & 16 & 3 & 3 \\
\hline Mobile 9 & 120 & 16 & 4 & 3 \\
\hline Mobile 10 & 340 & 128 & 6 & 5 \\
\hline Sum & 1535 & 496 & 37 & 51 \\
\hline
\end{tabular}


A decision matrix is created according to Eq. 4 and shown in Table 7.

Table 8

Normalization of the Decision Matrix

\begin{tabular}{ccccc}
\hline Goal Type & Min & Max & Max & Max \\
\hline Weights & 0.60338 & 0.13639 & 0.19567 & 0.06456 \\
Models & Price & Internal Storage & RAM & Brand \\
Mobile 1 & 0.05212 & 0.03226 & 0.05405 & 0.09804 \\
Mobile 2 & 0.07166 & 0.06452 & 0.05405 & 0.17647 \\
Mobile3 & 0.08469 & 0.12903 & 0.10811 & 0.17647 \\
Mobile 4 & 0.12052 & 0.12903 & 0.10811 & 0.01961 \\
Mobile 5 & 0.08795 & 0.12903 & 0.08108 & 0.07843 \\
Mobile 6 & 0.09121 & 0.06452 & 0.08108 & 0.09804 \\
Mobile 7 & 0.12052 & 0.12903 & 0.16216 & 0.13725 \\
Mobile 8 & 0.07166 & 0.03226 & 0.08108 & 0.05882 \\
Mobile 9 & 0.07818 & 0.03226 & 0.10811 & 0.05882 \\
Mobile 10 & 0.22150 & 0.25806 & 0.16216 & 0.09804 \\
\hline
\end{tabular}

The weightages of the four criteria are already found out by applying AHP in the theoretical section under the sub-section of 3.1 which are as follows: $w_{\text {price }}=0.60338, w_{\text {int }}$ sto $=0.13639, w_{R A M}=0.19567$, $w_{\text {brand }}=0.06456$. Normalization of the decision matrix (shown in Table 7) is done using Eq. 5. The normalized decision matrix is shown in Table 8.

Table 9

Weighted Normalized Matrix

\begin{tabular}{ccccccc}
\hline Goal Type & Min & Max & Max & Max & & \\
\cline { 1 - 4 } Models & Price & Internal Storage & RAM & Brand & S $_{+\mathrm{i}}$ & 0.03145 \\
\hline Mobile 1 & 0.03145 & 0.00440 & 0.01058 & 0.00633 & 0.02131 & 0.04324 \\
Mobile 2 & 0.04324 & 0.00880 & 0.01058 & 0.01139 & 0.03077 & 0.05110 \\
Mobile3 & 0.05110 & 0.01760 & 0.02115 & 0.01139 & 0.05015 & 0.051272 \\
Mobile 4 & 0.07272 & 0.01760 & 0.02115 & 0.00127 & 0.04002 & 0.07272 \\
Mobile 5 & 0.05307 & 0.01760 & 0.01586 & 0.00506 & 0.03853 & 0.05307 \\
Mobile 6 & 0.05503 & 0.00880 & 0.01586 & 0.00633 & 0.03099 & 0.05503 \\
Mobile 7 & 0.07272 & 0.01760 & 0.03173 & 0.00886 & 0.05819 & 0.07272 \\
Mobile 8 & 0.04324 & 0.00440 & 0.01586 & 0.00380 & 0.02406 & 0.04324 \\
Mobile 9 & 0.04717 & 0.00440 & 0.02115 & 0.00380 & 0.02935 & 0.04717 \\
Mobile 10 & 0.13365 & 0.03520 & 0.03173 & 0.00633 & 0.07326 & 0.13365 \\
\hline
\end{tabular}

The weighted normalized matrix is formed using Eq. (6) and similarly, $S_{+i}$ and $S_{-i}$ are also calculated for each alternative according to Eq. (7) and Eq. (8). The weighted normalized matrix and the $S_{+i}$ and $S_{-i}$ values are shown in Table 9 above.

Table 10

The Relative Significance and Quantitative Utility Values of Each Alternative

\begin{tabular}{cccc}
\hline Models & Relative Significance $\left(\mathrm{Q}_{\mathrm{i}}\right)$ & Quantitative Utility $\left(\mathrm{U}_{\mathrm{i}}\right)$ & $\%$ \\
\hline Mobile 1 & 1 & 0.85262 & 85.262 \\
Mobile 2 & 0.12186 & 0.91930 & 91.930 \\
Mobile3 & 0.10390 & 0.68523 & 68.523 \\
Mobile 4 & 0.11202 & 0.80515 & 80.515 \\
Mobile 5 & 0.08350 & 0.72587 & 72.587 \\
Mobile 6 & 0.09811 & 0.83435 & 83.435 \\
Mobile 7 & 0.08845 & 0.79758 & 79.758 \\
Mobile 8 & 0.10167 & 0.79097 & 79.097 \\
Mobile 9 & 0.09719 & 0.79533 & 79.533 \\
\hline Mobile 10 & 0.09638 & & 0.0967 \\
\hline
\end{tabular}


The priority values or relative significance $\left(Q_{i}\right)$ of each alternative are calculated using Eq. 11 . Here, the $Q_{i}$ value for Model 1 is the $Q_{\max }$ value since it is the highest and best choice alternative. Now, the quantitative utility values $\left(U_{i}\right)$ for each alternative with respect to $Q_{\max }$ are calculated using Eq. 12 . Table 10 shows the priority values and the quantitative utility of all the alternatives.

\subsection{Application of ARAS}

Table 11

Decision Matrix

\begin{tabular}{ccccc}
\hline $\begin{array}{c}\text { Goal Type } \\
\text { Models }\end{array}$ & $\begin{array}{c}\text { Min } \\
\text { Price }\end{array}$ & $\begin{array}{c}\text { Max } \\
\text { Internal Storage }\end{array}$ & $\begin{array}{c}\text { Max } \\
\text { RAM }\end{array}$ & $\begin{array}{c}\text { Max } \\
\text { Brand }\end{array}$ \\
\hline A0 & 80 & 128 & 6 & 9 \\
Mobile 1 & 80 & 16 & 2 & 5 \\
Mobile 2 & 110 & 32 & 4 & 9 \\
Mobile 3 & 130 & 64 & 4 & 9 \\
Mobile 4 & 185 & 64 & 3 & 4 \\
Mobile 5 & 135 & 64 & 3 & 5 \\
Mobile 6 & 140 & 32 & 6 & 7 \\
Mobile 7 & 185 & 64 & 3 & 3 \\
Mobile 8 & 110 & 16 & 4 & 3 \\
Mobile 9 & 120 & 16 & 6 & 5 \\
Mobile 10 & 340 & 128 & & \\
\hline
\end{tabular}

Table 11 shows the decision matrix according to Eq. 4 and $A 0$ denotes the most desired values of each criteria. Taking the smallest value for non-beneficial criteria's (i.e. price) and the largest value for beneficial criteria's (i.e. internal storage, RAM and brand) as $A 0$ values which is shown in Table 11.

Table 12

Normalization of the Decision Matrix

\begin{tabular}{ccccc}
\hline Goal Type & Min & Max & Max & Max \\
\hline Weights & 0.60338 & 0.13639 & 0.19567 & 0.06456 \\
Models & Price & Internal Storage & RAM & Brand \\
A0 & 0.14284 & 0.20513 & 0.13953 & 0.15000 \\
Mobile 1 & 0.14284 & 0.02564 & 0.04651 & 0.08333 \\
Mobile 2 & 0.10388 & 0.05128 & 0.04651 & 0.15000 \\
Mobile3 & 0.08790 & 0.10256 & 0.09302 & 0.15000 \\
Mobile 4 & 0.06177 & 0.10256 & 0.09302 & 0.01667 \\
Mobile 5 & 0.08465 & 0.10256 & 0.06977 & 0.06667 \\
Mobile 6 & 0.08162 & 0.05128 & 0.06977 & 0.08333 \\
Mobile 7 & 0.06177 & 0.10256 & 0.13953 & 0.11667 \\
Mobile 8 & 0.10388 & 0.02564 & 0.06977 & 0.05000 \\
Mobile 9 & 0.09523 & 0.02564 & 0.09302 & 0.05000 \\
Mobile 10 & 0.03361 & 0.20513 & 0.13953 & 0.08333 \\
\hline
\end{tabular}

Normalization of the beneficial criteria i.e. internal storage, RAM and brand are done using Eq. 13 and the normalization of the non-beneficial criteria i.e. price is done using Eq. 14 and Eq. 15 respectively. The above Table 12 shows the normalized decision matrix.

Table 13

Weighted Normalized Decision Matrix

\begin{tabular}{cccccc}
\hline Models & Price & Internal Storage & RAM & Brand & Sum \\
\hline A0 & 0.08619 & 0.02798 & 0.02730 & 0.00968 & 0.15115 \\
Mobile 1 & 0.08619 & 0.00350 & 0.00910 & 0.00538 & 0.10417 \\
Mobile 2 & 0.06268 & 0.00699 & 0.00910 & 0.00968 & 0.08846 \\
Mobile3 & 0.05304 & 0.01399 & 0.01820 & 0.00968 & 0.09491 \\
Mobile 4 & 0.03727 & 0.01399 & 0.01820 & 0.00108 & 0.07054 \\
Mobile 5 & 0.05107 & 0.01399 & 0.01365 & 0.00430 & 0.08302 \\
Mobile 6 & 0.04925 & 0.00699 & 0.01365 & 0.00538 & 0.07528 \\
Mobile 7 & 0.03727 & 0.01399 & 0.02730 & 0.00753 & 0.08609 \\
Mobile 8 & 0.06268 & 0.00350 & 0.01365 & 0.00323 & 0.08306 \\
Mobile 9 & 0.05746 & 0.00350 & 0.01820 & 0.00323 & 0.08239 \\
Mobile 10 & 0.02028 & 0.02798 & 0.02730 & 0.00538 & 0.08094 \\
\hline
\end{tabular}


Table 13 shows the weighted normalized matrix. Using the same weightages of the criteria, the weighted values of the normalized matrix are calculated using Eq. (16). Further, the summation of each row for every alternative are also found out by using Eq. (17) and shown in Table 13 above. These sum values are nothing but the optimality function $\left(S_{i}\right)$ values of each alternatives.

Table 14

Degree of Utility of Each Alternative

\begin{tabular}{|c|c|c|c|}
\hline Models & Optimality Function $\left(\mathrm{S}_{\mathrm{i}}\right)$ & Degree of Utility $\left(\mathrm{U}_{\mathrm{i}}\right)$ & $\%$ \\
\hline A0 & 0.15115 & 1 & 100 \\
\hline Mobile 1 & 0.10417 & 0.68915 & 68.915 \\
\hline Mobile 2 & 0.08846 & 0.58525 & 58.525 \\
\hline Mobile3 & 0.09491 & 0.62793 & 62.793 \\
\hline Mobile 4 & 0.07054 & 0.46666 & 46.666 \\
\hline Mobile 5 & 0.08302 & 0.54924 & 54.924 \\
\hline Mobile 6 & 0.07528 & 0.49801 & 49.801 \\
\hline Mobile 7 & 0.08609 & 0.56958 & 56.958 \\
\hline Mobile 8 & 0.08306 & 0.54950 & 54.950 \\
\hline Mobile 9 & 0.08239 & 0.54505 & 54.505 \\
\hline Mobile 10 & 0.08094 & 0.53548 & 53.548 \\
\hline
\end{tabular}

The degree of utility $\left(U_{i}\right)$ for all the alternatives are calculated by using Eq. 18 and shown in Table 14 where the $S_{0}$ value is 0.15115 .

\section{Results and Discussions}

The quantitative utility values in case of COPRAS and the degree of utility in case of ARAS are calculated for all the alternatives under the research methodology section. The outcome results from both the methods are explained in details in the following sub-section.

\subsection{Outcome results from COPRAS}

\section{Table 15}

Ranking of the Models by COPRAS Method

\begin{tabular}{lccccc}
\hline & & & Models & Quantitative Utility & Rank \\
\hline Models 1 & 100 & 1 & Models 6 & 72.587 & 9 \\
Models 2 & 85.262 & 3 & Models 7 & 83.435 & 4 \\
Models 3 & 91.930 & 2 & Models 8 & 79.758 & 6 \\
Models 4 & 68.523 & 10 & Models 9 & 79.097 & 8 \\
Models 5 & 80.515 & 5 & Models 10 & 79.533 & 7 \\
\hline
\end{tabular}

From Table 15 it can be seen that Model 1 has obtain the highest quantitative utility value i.e. 100\% followed by Model 3 (91.930\%) and Model 2 (85.262\%), hence Model 1 can be termed as the best mobile model. The ranking of all the mobile models according to the decreasing quantitative utility values are shown in Table 15. The preference ranking order of the models based on COPRAS technique can be given as:

$$
\mathrm{M} 1>\mathrm{M} 3>\mathrm{M} 2>\mathrm{M} 7>\mathrm{M} 5>\mathrm{M} 8>\mathrm{M} 10>\mathrm{M} 9>\mathrm{M} 6>\mathrm{M} 4
$$

\subsection{Outcome Results from $A R A S$}

\section{Table 16}

Ranking of the Models by ARAS Method

\begin{tabular}{cccccc}
\hline Models & Degree of Utility $\left(\mathrm{U}_{\mathrm{i}}\right)$ & Rank & Models & Degree of Util- & Rank \\
\hline Models 1 & 68.915 & 1 & Models 6 & 49.801 & 9 \\
Models 2 & 58.525 & 3 & Models 7 & 56.958 & 4 \\
Models 3 & 62.793 & 2 & Models 8 & 54.950 & 5 \\
Models 4 & 46.666 & 10 & Models 9 & 54.505 & 7 \\
Models 5 & 54.924 & 6 & Models 10 & 53.548 & 8 \\
\hline
\end{tabular}


The degree of utility is highest for Model 1 i.e. 68.915\% followed by Model 3 (62.793\%) and Model 2 (58. 525\%), hence Model 1 can be termed as the best mobile model. The ranking of the mobile models is given in Table 16. The preference ranking order of the models can be given as follows:

$$
\mathrm{M} 1>\mathrm{M} 3>\mathrm{M} 2>\mathrm{M} 7>\mathrm{M} 8>\mathrm{M} 5>\mathrm{M} 9>\mathrm{M} 10>\mathrm{M} 6>\mathrm{M} 4
$$

\subsection{Comparisons of the Ranking by COPRAS and ARAS}

Table 17

Ranking Comparisons

\begin{tabular}{ccc}
\hline Rank & COPRAS & ARAS \\
\hline Rank 1 & Model 1 & Model 1 \\
Rank 2 & Model 3 & Model 3 \\
Rank 3 & Model 2 & Model 2 \\
Rank 4 & Model 7 & Model 8 \\
Rank 5 & Model 5 & Model 5 \\
Rank 6 & Model 8 & Model 9 \\
Rank 7 & Model 10 & Model 10 \\
Rank 8 & Model 9 & Model 6 \\
Rank 9 & Model 6 & Model 4 \\
\hline
\end{tabular}

Table 17 shows that the outcome results and the ranking of the models are more or less same for both the methods. Both the methods are giving the same output that Model 1 and Model 4 is the best model and the worst model respectively. Not only these, but also the first three positions and the last two positions of the models are exactly same for both the methods although there is a slight change in ranking of the middle-order alternatives. Table 17 shows the ranking comparisons of the models. The ranking comparisons are also shown graphically in the Fig. 1 below.

\section{Ranking Comparisons}

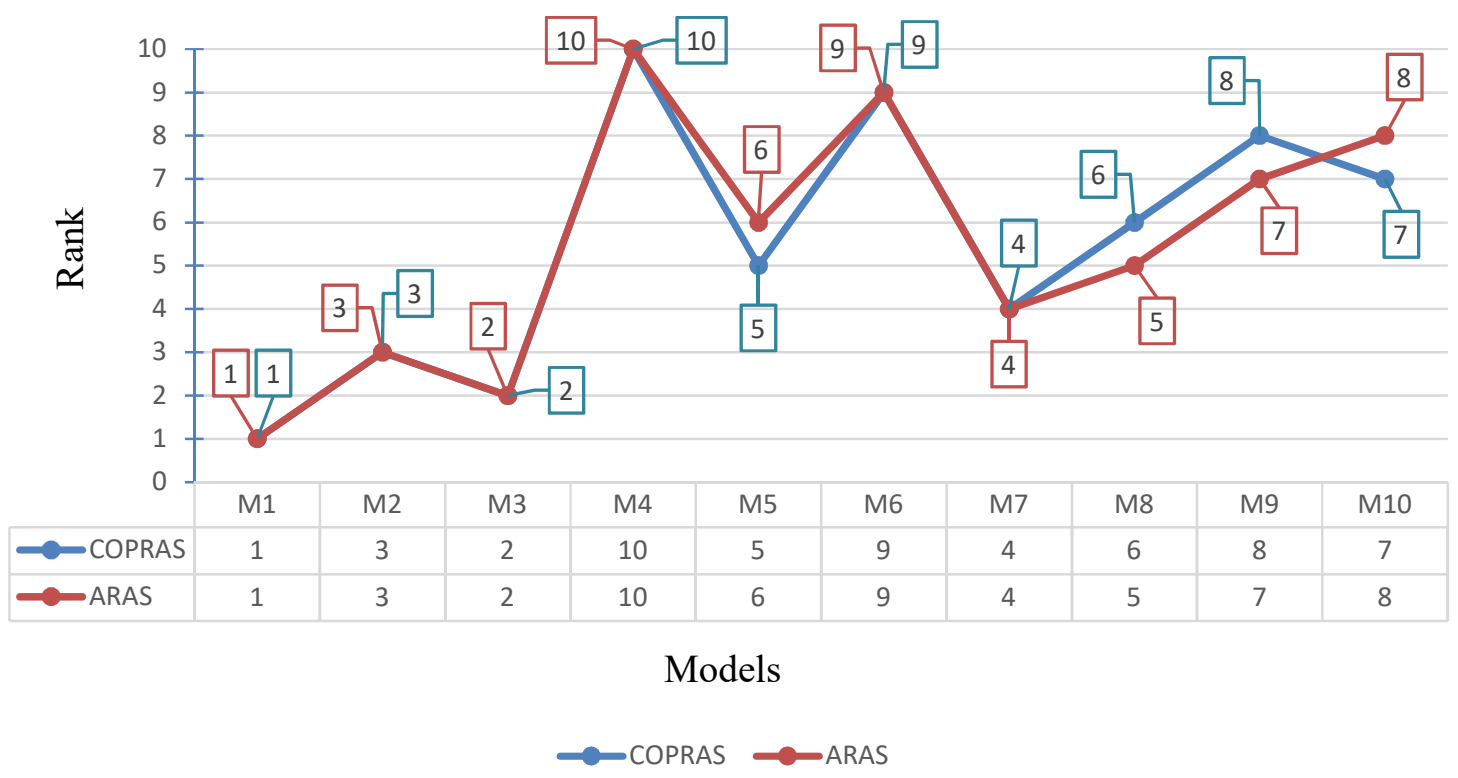

Fig. 1. Ranking Comparisons of the Mobile Models by COPRAS and ARAS

\section{Conclusions}

From this whole analysis it can be concluded that Redmi 7a (Model 1) is the best mobile model among these 10 models available in the market followed by Samsung J7 (Model 3) and Samsung Galaxy A10 (Model 2) in the second and third position respectively. If someone wants to buy a mobile phone he/she 
can go for Redmi 7a and if it is not available in the market he/she can go for Model 3 or Model 2, but the last rank model i.e. Oppo K1 (Model 4) should be avoided since there are lots of other options also available in the market.

This analysis has been accomplished based on four criteria, but there are also other criteria that can be considered along with these e.g. screen size, battery, display resolution, camera to get more precise and accurate results. The same problem can also be analyzed by implementing other MCDM tools like TOPSIS, VIKOR, PROMETHEE, MOORA etc. and the results can be compared with these outcomes. COPRAS and ARAS methodology is not limited to these types of applications only but can also be applied in selecting other electronic gadgets and household appliances e.g. laptop, refrigerator, camera, washing machine etc. and taking other strategic decisions.

\section{Acknowledgements}

We would like to thanks all the professors and colleagues of our institution who supported us in each and every step, we would like to thank all the authors of the papers from which we have taken some valuable information that helped us complete this article in a proper way and thank to those common people who gave their valuable views about mobile phones and lastly, thank to all who directly or indirectly associated with this research work.

\section{References}

Adali, E. A., \& Iş1k, A. T. (2016). Air conditioner selection problem with COPRAS and ARAS methods. Manas Sosyal Araştırmalar Dergisi, 5(2), 124-138.

Adalı, E., \& Işık, A. (2017). The multi-objective decision making methods based on MULTIMOORA and MOORA for the laptop selection problem. International Journal of Industrial Engineering, Springer, 13, 229-237.

Andruškevicius, A. (2005). Evaluation of contractors by using COPRAS - The multiple criteria method. Technological and Economic Development of Economy, 11(3), 158-169.

Anyaeche, C., Ighravwe, D., \& Asokeji, T. (2017). Project portfolio selection of banking services using COPRAS and Fuzzy-TOPSIS. Journal of Project Management, 2(2), 51-62.

Banaitiene, N., Banaitis, A., Kaklauskas, A., \& Zavadskas, E.K. (2008). Evaluating the life cycle of a building: A multivariant and multiple criteria approach. Omega, 36(3), $429-441$.

Barak, S., Mehrgini, B., Maghsoudlou, H., \& Branch, Q. (2014). Multi-criteria decision making approach to candidate well selection for hydraulic fracturing treatment, CIE44 \& IMSS" 14 Proceedings, 14-16 October, Istanbul / Turkey, 2092-2106.

Bhattacharyya, A., \& Chakraborty, S. (2014). A DEA-TOPSIS-based approach for performance evaluation of Indian technical institutes. Decision Science Letters, 3(3), 397-410.

Bhole, G.P., \& Deshmukh, T. (2018). Multi-criteria decision making (MCDM) methods and its applications. International Journal for Research in Applied Science \& Engineering Technology (IJRASET), 6(5), 899-915.

Biswas, T., \& Saha, P. (2019). Selection of commercially available scooters by new MCDM method. International Journal of Data and Network Science, 3(2), 137-144.

Bose, G., \& Chatterjee, N. (2016). Fuzzy hybrid MCDM approach for selection of wind turbine service technicians. Management Science Letters, 6(1), 1-18.

Brans, J.P. (1982). L'ingénièrie de la décision; Elaboration d'instruments d'aide à la décision. La méthode PROMETHEE. Organized by Nadeau, R. and Landry, M., L'aide à la décision: Nature, Instruments et Perspectives d'Avenir, Québec, Canada, Presses de l'Université Laval, 183-213.

Brauers, W.K.M., \& Zavadskas, E.K. (2006). The MOORA method and its applications to privatization in a transition economy. Control and cybernetics, 35(2), 445-469.

Brauers, W.K.M., \& Zavadskas, E.K. (2009). Multi objectives optimization with discrete alternatives on the basis of ratio analysis. Intellectual economics, 2(6), 30-41.

Buckley, J.J. (1985). Fuzzy hierarchical analysis. Fuzzy Sets Systems, 17(1), 233-247. 
Bulut, E., Duru, O., Keçeci, T., \& Yoshida, S. (2012). Use of consistency index, expert prioritization and direct numerical inputs for generic fuzzy-AHP modeling: A process model for shipping asset management. Expert Systems with Applications, 39(2), 1911-1923.

Celik, M., Deha, E.I., \& Ozok, A.F. (2009). Application of fuzzy extended AHP methodology on shipping registry selection: The case of Turkish maritime industry. Expert Systems with Applications, 36(1), 190-198.

Chaghooshi, A., Arab, A., \& Dehshiri, S. (2016). A fuzzy hybrid approach for project manager selection. Decision Science Letters, 5(3), 447-460.

Chang, D.Y. (1996). Applications of the extent analysis method on Fuzzy AHP. European Journal of Operational Research, 95(3), 649-655.

Chatterjee, N., \& Bose, G. (2013a). Selection of vendors for wind farm under fuzzy MCDM environment. International Journal of Industrial Engineering Computations, 4(4), 535-546.

Chatterjee, N., \& Bose, G. (2013b). A COPRAS-F base multi-criteria group decision making approach for site selection of wind farm. Decision Science Letters, 2(1), 1-10.

Chatterjee, P., \& Chakraborty, S. (2014). Flexible manufacturing system selection using preference ranking methods: A comparative study, International Journal of Industrial Engineering Computations, 5, 315-338.

Chung, E.S., \& Lee, K.S. (2009). Prioritization of water management for sustainability using hydrologic simulation model and multi criteria decision making techniques. Journal of Environmental Management, 90, 1502-1511.

Das, M.C., Sarkar, B., \& Ray, S. (2012). A framework to measure relative performance of indian technical institutions using integrated fuzzy AHP and COPRAS methodology. Socio-economic Planning Sciences, 46, 230-241.

Dey, S., \& Chakraborty, S. (2016). A study on the machinability of some metal alloys using grey TOPSIS method. Decision Science Letters, 5(1), 31-44.

Durán, O., \& Aguilo, J. (2008). Computer-aided machine tool selection based on a fuzzy-AHP approach. Expert Systems with Applications, 34, 1787-1794.

Efendigil, T., Önüt, S., \& Kongar, E. (2008). A holistic approach for selecting a third-party reverse logistics provider in the presence of vagueness. Computers \& Industrial Engineering, 54, 269-286.

Garg, R., \& Jain, D. (2017). Fuzzy multi-attribute decision making evaluation of e-learning websites using FAHP, COPRAS, VIKOR, WDBA. Decision Science Letters, 6(4), 351-364.

Geldermann, J., Spengler, T., \& Rentz, O. (2000). Fuzzy outranking for environmental assessment. Case study: Iron and steel making industry. Fuzzy Sets and Systems, 115(1), 45-65.

Ghadikolaei, S., Esbouei S.K., \& Antucheviciene, J. (2014). Applying fuzzy MCDM for financial performance evaluation of Iranian companies. Technological and Economic Development of Economy, 20(2), 274-291.

Hwang, C.L., Lai, Y.J., \& Liu, T.Y. (1993). A new approach for multiple objective decision making. Computers and Operational Research, 20(8), 889-899.

Hwang, C.L., \& Yoon, K. (1981). Multiple attributes decision making methods and applications. Berlin: Springer.

Işık, A., \& Adal1, E. (2016). A comparative study for the agricultural tractor selection problem. Decision Science Letters, 5(4), 569-580.

Kaklauskas, A., Zavadskas, E.K., Raslanas, S., Ginevicius, R., Komka, A., \& Malinauskas, P. (2006). Selection of low e-windows in retrofit of public buildings by applying multiple criteria method COPRAS: A Lithuanian case. Energy and Buildings, 38(5), 454-462.

Karande, P., \& Chakraborty, S. (2012). A Fuzzy-MOORA approach for ERP system selection. Decision Science Letters, 1(1), 11-21.

Karande, P., Zavadskas, E.K., \& Chakraborty, S. (2016). A study on the ranking performance of some MCDM methods for industrial robot selection problems. International Journal of Industrial Engineering Computations, 7(3), 399-422. 
Koganti, V., Menikonda, N., Anbuudayasankar, S., Krishnaraj, T., Athhukuri, R., \& Vastav, M. (2019). GRAHP TOP model for supplier selection in Supply Chain: A hybrid MCDM approach. Decision Science Letters, 8(1), 65-80.

Kowalski, K., Stagl, S., Madlener, R., \& Omann, I. (2009). Sustainable energy futures: Methodological challenges in combining scenarios and participatory multi-criteria analysis. European Journal of Operational Research, 197, 1063-1074.

Kumar, J., \& Roy, N. (2010). Hybrid method for vendor selection using neural network. International Journal of Computer Applications, 11, 35-40.

Kundakc1, N., \& Iş1k, A. (2016). Integration of MACBETH and COPRAS methods to select air compressor for a textile company. Decision Science Letters, 5(3), 381-394.

Kundakcı, N., Işık, A., \& Adal1, E. (2015). AHP ve MOORA Yöntemleri ile Klima Seçimi, Uluslararası Katılımlı Üretim AraG̣tırmaları Sempozyumu, 14-16 October, Ege University, Ġzmir.

Liu, F., Ding, F.Y., \& Lall, V. (2000). Using data envelopment analysis to compare vendors for vendor selection and performance improvement. Supply Chain Management: An International Journal, 5, 143-150.

Madic, M., Markovic, D., Petrovic, G., \& Radovanovic, M. (2014). Application of copras method for supplier selection. The 5th International Conference "Transport and Logistics".

Madurika, H.K.G.M., \& Hemakumara, G.P.T.S. (2015). GIS based analysis for suitability location finding in the residential development areas of greater Matara region. International Journal of Scientific \& Technology Research, 4(8), 96-105.

Marzouk, M., \& Abdelakder, E. (2019). On the use of multi-criteria decision making methods for minimizing environmental emissions in construction projects. Decision Science Letters, 8(4), 373-392.

Mirahmadi, S., Attafar, A., \& Ketabi, S. (2018). Developing a fuzzy ANP model for performance appraisal based on firm strategy. Decision Science Letters, 7(3), 243-256.

Mitra, S., \& Goswami, S.S. (2019a). Selection of the desktop computer model by AHP-TOPSIS hybrid MCDM methodology. International Journal of Research and Analytical Reviews, 6(1), 784-790.

Mitra, S., \& Goswami, S.S. (2019b). Application of integrated MCDM technique (AHP-SAW) for the selection of best laptop computer model. International Journal for Research in Engineering Application \& Management, 4(12), 1-6.

Mitra, S., \& Goswami, S.S. (2019c). Application of simple average weighting optimization method in the selection of best desktop computer model. Advanced Journal of Graduate Research, 6(1), 60-68.

Mitra, S., \& Kundu, S. (2017). Application of analytic hierarchy process for domestic refrigerator selection. International Journal of Emerging Technologies in Engineering Research, 5(12), 126-132.

Mitra, S., \& Kundu, S. (2018). Application of TOPSIS for best domestic refrigerator selection. International Journal of Research and Analytical Reviews, 5(3), 226-231.

Opricovic, S., \& Tzeng, G.H. (2004). The compromise solution by MCDM methods: A comparative analysis of VIKOR and TOPSIS. European Journal of Operational Research, 56(2), 445-455.

Opricovic, S., \& Tzeng, G.H. (2007). Extended VIKOR method in comparison with outranking methods. European Journal of Operational Research, 178(2), 514-529.

Paul, D., Agarwal, P., \& Chakraborty, S. (2016). Performance appraisal of Indian state police forces using ARAS method. Management Science Letters, 6(5), 361-372.

Prasad, K., \& Chakraborty, S. (2018). Application of the modified similarity-based method for cutting fluid selection. Decision Science Letters, 7(3), 273-286.

Prasad, K., Subbaiah, K., \& Prasad, M. (2017). Supplier evaluation and selection through DEA-AHPGRA integrated approach- A case study. Uncertain Supply Chain Management, 5(4), 369-382.

Qin, X.S., Huang, G.H., Chakma, A., \& Nie, X.H. (2008). A MCDM based expert system for climate change impact assessment and adaptation planning. A case study for the Georgia basin, Canada. Expert Systems with Applications, 34(3), 2164-2179.

Rathi, R., Khanduja, D., \& Sharma, S. (2016). A fuzzy MADM approach for project selection: a six sigma case study. Decision Science Letters, 5(2), 255-268.

Rostampour, S. (2012). An application of TOPSIS for ranking internet web browsers. Decision Science Letters, 1(2), 53-58. 
Rostamzadeh, R., \& Sofian, S. (2011). Prioritizing effective 7Ms to improve production systems performance using fuzzy AHP and fuzzy TOPSIS (Case Study). Expert System Applications, 38, 51665177.

Roy, B. (1968). Classement Et Choix en Présence de Points de Vue Multiples (la Méthode ELECTRE). La Revue d'Informatique et de Recherche Opérationelle (RIRO), 8, 57-75.

Saaty, T.L. (1980). The analytic hierarchy process. New York: McGraw-Hill.

Saaty, T.L. (2008). Decision making for leaders: The analytic hierarchy process for decisions in a complex world. Pittsburgh, Pennsylvania: RWS Publications.

Sowlati, T., Paradi, J.C., \& Suld, C. (2005). Information systems project prioritization using data envelopment analysis. Mathematical and Computer Modeling, 41(11-12), 1279-1298.

Sun, C.C. (2010). A performance evaluation model by integrating fuzzy AHP and fuzzy TOPSIS methods. Expert System Applications, 37(12), 7745-7754.

Tsoutsos, T., Drandaki, M., Frantzeskaki, N., Iosifidis, E., \& Kiosses, I. (2009). Sustainable energy planning by using multi-criteria analysis application in the island of crete. Energy Policy, 37, 1587-1600.

Tzeng, G.H., Lin, C.W., \& Opricovic, S. (2005). Multi-criteria analysis of alternative-fuel buses for public transportation. Energy Policy, 33, 1373-1383.

Vaillancourt, K., \& Waaub, J.P. (2004). Equity in international greenhouse gases abatement scenarios: A multi criteria approach. European Journal of Operational Research, 153, 489-505.

Velasquez, M., \& Hester, P.T. (2013). An analysis of multi-criteria decision making methods. International Journal of Operations Research, 10(2), 56-66.

Viteikiene, M., \& Zavadskas, E.K. (2007). Evaluating the sustainability of Vilnius city residential areas. Journal of Civil Engineering and Management, 8(2), 149-155.

Yang, C.L., Chuang, S.P., \& Huang, R.H. (2009). Manufacturing evaluation system based on AHP/ANP approach for wafer fabricating industry. Expert System Application, 36, 11369-11377.

Yazdani-Chamzini, A., \& Yakhchali, S. (2012). Handling equipment Selection in open pit mines by using an integrated model based on group decision making. International Journal of Industrial Engineering Computations, 3(5), 907-924.

Yoon, K. (1987). A reconciliation among discrete compromise situations. Journal of Operational Research Society, 38 (3), 277-286.

Zare, A., Feylizadeh, M., Mahmoudi, A., \& Liu, S. (2018). Suitable computerized maintenance management system selection using grey group TOPSIS and fuzzy group VIKOR: A case study. Decision Science Letters, 7(4), 341-358.

Zavadskas, E.K., Kaklauskas, A., Turskis, Z., \& Tamošaitien, J. (2008). Selection of the effective dwelling house walls by applying attributes values determined at intervals. Journal of Civil Engineering and Management, 14(2), 85-93.

Zavadskas, E.K., \& Turskis, Z. (2010). A new additive ratio assessment (ARAS) method in multicriteria decision-making. Technological and Economic Development of Economy, 16(2), 159-172.

Zavadskas, E.K., Turskis, Z., \& Vilutiene, T. (2010). Multiple criteria analysis of foundation instalment alternatives by applying Additive Ratio Assessment (ARAS) method. Archives of Civil and Mechanical Engineering, 10(3), 123-141.

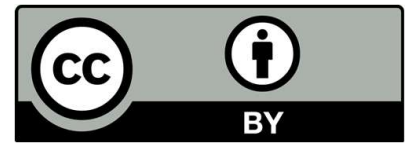

(C) 2020 by the authors; licensee Growing Science, Canada. This is an open access article distributed under the terms and conditions of the Creative Commons Attribution (CC-BY) license (http://creativecommons.org/licenses/by/4.0/). 